\title{
VEGFR3 inhibition chemosensitizes lung adenocarcinoma A549 cells in the tumor-associated macrophage microenvironment through upregulation of p53 and PTEN
}

\author{
YA LII $^{1 *}$, YAGUANG WENG $^{1 *}$, LIANG ZHONG $^{1}$, HUIMIN CHONG $^{1}$, SICHENG CHEN $^{2}$, YANTING SUN $^{1}$, \\ WANG $\mathrm{LI}^{1}$ and QIONG SHI \\ ${ }^{1}$ Department of Laboratory Medicine, M.O.E., Key Laboratory of Laboratory Medicine Diagnostics, \\ Chongqing Medical University, Chongqing 400016; ${ }^{2}$ Department of Clinical Medicine, \\ Xinxiang Medical University, Xinxiang, Henan 453003, P.R. China
}

Received December 21, 2016; Accepted May 25, 2017

DOI: 10.3892/or.2017.5969

\begin{abstract}
In lung adenocarcinoma, loss of p53 and PTEN in tumors are associated with decreased response to chemotherapy and decreased survival. A means to pharmacologically upregulate $\mathrm{p} 53$ and PTEN protein expression could improve the prognosis of patients with p53- and PTEN-deficient tumors. In the present study we revealed that vascular endothelial growth factor receptor 3 (VEGFR3) inhibition in lung adenocarcinoma cells was associated with improved expression levels of both p53 and PTEN in the tumor-associated macrophage (TAM) microenvironment. Inhibition of VEGFR3 in lung adenocarcinoma cells was associated with growth arrest and decreased migration and invasion. The upregulation of $\mathrm{p} 53$ and PTEN protein expression after VEGFR3 inhibition decreased chemotherapy resistance and improved chemosensitivity in co-cultured A549 cells in which p53 and PTEN expression were decreased. Finally, we demonstrated that TAMs promoted the expression of VEGF-C and its receptor VEGFR3. Western blot analysis revealed the co-cultured A549 cells with TAMs are a primary source of VEGF-C and VEGFR3 in the tumor microenvironment. Our studies revealed that VEGFR3 inhibition may be a pharmacological means to upregulate p53 and PTEN protein expression and improve the outcome of patients with p53- and PTEN-deficient tumors.
\end{abstract}

Correspondence to: Professor Qiong Shi, Department of Laboratory Medicine, M.O.E., Key Laboratory of Laboratory Medicine Diagnostics, Chongqing Medical University, Chongqing 400016, P.R. China

E-mail: anniesq8718@aliyun.com

*Contributed equally

Key words: tumor-associated macrophage, vascular endothelial growth factor receptor 3, A549 cells, p53, PTEN, chemosensitivity

\section{Introduction}

Non-small cell lung cancer (NSCLC), comprised of squamous cell carcinoma, adenocarcinoma and large cell undifferentiated carcinoma, is the most common type of lung cancer (1). Gene and relevant proteins play a vital role in the pathophysiological mechanism of NSCLC (2), and cause non-sensitivity of NSCLC to chemotherapy (3), resulting in NSCLC being the most common cause of cancer-related mortality worldwide (4). In the development of NSCLC, p53 and PTEN, two tumor-suppressor genes play an essential role in the regulation of the cell cycle, apoptosis and chemotherapy sensitivity of tumor cells (5). Thus, it is necessary to develop novel drug targets based on the relevant molecular genes and proteins.

Doxorubicin can inhibit the activities of DNA and topoisomerase II to block DNA synthesis and relevant gene transcription, thus resulting in cell apoptosis and the inhibition of tumor cell growth $(6,7)$. There are some clinical studies that have demonstrated that the combination of doxorubicin with other chemotherapeutic drugs functions well as a treatment for lung carcinoma (8). However, the efficacy of chemotherapeutic drugs exhibit a limitation in the treatment of lung carcinoma. Lung carcinoma cells may readily be resistant to the drugs in clinical application, significantly decreasing the therapeutic efficacy of chemotherapy. Therefore, the identification and development of novel methods for improving chemotherapy sensitivity are significant in improving the clinical treatment effect (9).

The progression of NSCLC is highly influenced by the immune response of the host and the inflammatory cells in the tumor microenvironment (10). Among the host inflammatory cells, macrophages play a vital role. Macrophages have functional plasticity and can change their functional properties repeatedly in response to microenvironmental changes in tumors (11). The two extremes of polarized macrophages are named M1 and M2 macrophages (12). When macrophages are exposed to lipopolysaccharides (LPS), they are polarized to M1 macrophages and exert antitumor activities. When they are exposed to Th2 cytokines, such as IL-4/IL-13, they are 
polarized to M2 macrophages and promote the activities of tumors (13). M2 macrophages compared with M1 macrophages produce low levels of tumor necrosis factor- $\alpha$ (TNF- $\alpha$ ), and IL-6. M2 macrophages also express surface markers such as CD206 (a mannose receptor) (14).

Tumor-associated macrophages (TAMs) are mainly a type of M2 macrophages and have been reported to play many roles in the tumor microenvironment (15). In addition to promoting angiogenesis and suppressing antitumor activity, recent studies revealed that TAMs can promote chemotherapy resistance (16). TAMs can promote tumor cells into secreting a large number of angiogenic factors including both vascular endothelial growth factor A (VEGF-A) and VEGF-C (17-19). VEGF-A has a definite effect in tumor angiogenesis, whereas VEGF-C has a primary role in lymphangiogenesis. Recently, VEGF proteins were reported to directly impact tumor cells. Vascular endothelial growth factor receptor 2 (VEGFR2), the primary receptor for VEGF-A, is expressed on glioma cells and supports tumor cell growth, migration, and angiogenesis $(20,21)$.

Less is known about the impacts of VEGF-C and VEGF-D on cancer cells. VEGF-C levels are related to the prognosis of patients $(22,23)$ and downregulation of VEGF-C results in decreased breast cancer metastases (24). Similarly, inhibition of VEGFR3 (primary receptor for VEGF-C/VEGF-D) results in decreased growth and metastasis in breast and pancreatic tumor models (25-27). Most recently, soluble VEGFR3, used as a means to inhibit VEGF-C/VEGF-D, was found to decrease carcinogenesis in a murine model of skin carcinogenesis, suggesting a role for VEGFR3 in early tumor events (28).

In the lung adenocarcinoma A549 cell line, we revealed that TAMs can promote tumor cells to produce high levels of VEGF-C and VEGFR3. We demonstrated that VEGFR3 inhibition resulted in cell cycle arrest, apoptosis, and decreased migration and invasion of A549 cells in the tumor microenvironment. In addition, VEGFR3 inhibition was associated with decreased p-extracellular signal-regulated kinase (p-ERK), Bcl-2, MMP-2 and improved p53 and PTEN protein expression. Furthermore, VEGFR3 inhibition and its resulting increased expression of p53 and PTEN were associated with significant increased chemosensitivity in vivo. This strongly supports VEGFR3 as a drug target in lung adenocarcinoma.

\section{Materials and methods}

Cell preparations. THP-1 and A549 cell lines were obtained from the American Type Culture Collection (ATCC; Manassas, VA, USA) and cultured in RPMI-1640 media (Hyclone, USA) supplemented with $10 \%$ fetal bovine serum (Gibco, USA), $100 \mathrm{U} /$ $\mathrm{ml}$ penicillin and streptomycin (Invitrogen; Thermo Fisher Scientific, Inc.) at $37^{\circ} \mathrm{C}$ in a $5 \% \mathrm{CO}_{2}$ humidified incubator. To generate PMA-treated THP-1 macrophages, $1 \times 10^{6}$ THP-1 cells were seeded into a 6-well plate and treated with PMA (320 nM) for $48 \mathrm{~h}$. To generate M2-polarized THP-1 macrophages, THP-1 cells were treated with $320 \mathrm{nM}$ PMA for $48 \mathrm{~h}$, and then cultured with $20 \mathrm{ng} / \mathrm{ml} \mathrm{IL}-4$ for another $48 \mathrm{~h}$. To generate M1-polarized THP-1 macrophages, THP-1 cells were treated with $320 \mathrm{nM}$ PMA for $72 \mathrm{~h}$ and then cultured with $100 \mathrm{ng} / \mathrm{ml}$ LPS for $24 \mathrm{~h}$.

Flow cytometry. After inducing THP-1 cells by PMA for $48 \mathrm{~h}, 1 \times 10^{5}$ PMA-treated THP-1 macrophages were washed two times and resuspended in $1 \mathrm{ml}$ of phosphate-buffered saline (PBS). For surface markers, cells were incubated with FITC-CD14 mAb or FITC-CD206 mAb (both from BioLegend, San Diego, CA, USA) at $37^{\circ} \mathrm{C}$ in a $5 \% \mathrm{CO}_{2}$ humidified incubator for $30 \mathrm{~min}$, then washed two times with PBS. Following the final washing step, labeled cells were analyzed by flow cytometry on a FACScan flow cytometer using CellQuest software (BD Biosciences, USA).

RNA isolation and RT-PCR. Total RNA was isolated with an RNA extraction kit (Takara, Shigaken, Japan), and the concentration of total RNA was assessed spectrophotometrically. RNA $(2 \mu \mathrm{g})$ was converted to complementary DNA by an RT-PCR Bead kit (Takara) according to the manufacturer's protocol. The amplification sequence was 35 cycles at $94^{\circ} \mathrm{C}$ for $30 \mathrm{sec}, 58^{\circ} \mathrm{C}$ for $30 \mathrm{sec}$ and $70^{\circ} \mathrm{C}$ for $1 \mathrm{~min}$. The oligonucleotide primer sequences were as follows: IL-6 forward, 5'-AACCTG AACCTTCCAAAGATGG-3' and reverse, 5'-TCTGGCTTGT TCCTCACTACT-3'; $\beta$-actin forward, 5'-TGGCCCCAGCAC AATGAA-3' and reverse, 5'-CTAAGTCATAGTCCGCCTAG AAGCA-3'; VEGF-C forward, 5'-CACGAGCTACCTCAGC AAGA-3' and reverse, 5'-GCTGCCTGACACTGTGGTA-3'; VEGF-D forward, 5'-TGTAAGTGCTTGCCAACAGC-3' and reverse, 5'-GTGGATTTTCCTCCTGCAAA-3'; VEGFR3 forward, 5'-GTACATGCCAACGACACAGG-3' and reverse, 5'-TGATGAATGGCTGCTCAAAC-3'; p53 forward, 5'-ACG GTGACACGCTTCCCTGGATTGG-3' and reverse, 5'-CTGT CAGTGGGGAACAAGAAGTGGAGA-3'; PTEN forward, 5'-AGGGAGTCACAATTCCCAGTC-3' and reverse, 5'-AGG TTTCCTCTGGTCCTGGTAT-3'; and GAPDH forward, 5'-ATGTTCGTCATGGGTGTGAA-3' and reverse, 5'-GGTG CTAAGCAGTTGGTGGT-3'.

Detection of the cytokine profile of macrophages. PMA-treated THP-1 macrophages and M1/M2-polarized THP-1 macrophages ( $1 \times 10^{5}$ cells) were cultured with serum-free RPMI-1640 medium for two days. Culture supernatants were collected from these cells and stored at $-80^{\circ} \mathrm{C}$ for less than 3 months. The cytokine level was assessed with TNF- $\alpha$ ELISA kits (ExCell Biology, Inc., Shanghai, China).

Macrophage and A549 cell co-culture. After a thorough wash to remove all PMA, M2 macrophages (upper inserts, $1.0 \times 10^{6}$ cells/well, $2 \mathrm{ml}$ ) were co-cultured with A549 cells (lower inserts, $3.0 \times 10^{5}$ cells/well, $2 \mathrm{ml}$ ) with serum-free media in a 6 -well plate without direct contact. After $48 \mathrm{~h}$ of co-culture, the co-cultured supernatant was collected and used for subsequent experiments.

Cell migration assay. A549 cells ( $3 \times 10^{5}$ cells/well) were seeded into a 6 -well plate. When the cell density reached $85 \%$, the cell layers were then damaged with a micropipette to create a linear wound $2 \mathrm{~mm}$ in width. The co-cultured supernatant (diluted 1:5 with serum-free media) was added. MAZ51 (a VEGFR3 inhibitor; $5 \mu \mathrm{M}$; Cayman Chemical, Ann Arbor, MI, USA) in the co-cultured supernatant (diluted 1:5 with serum-free media) was also added. All cells were incubated for 24 and $48 \mathrm{~h}$. Images were acquired using a microscope (Nikon Corporation, Tokyo, Japan) and the results are expressed as the percentage of promotion and inhibition of migration of treated cells compared with untreated cells. 
Invasion assay. The invasion assay was conducted using Transwell cell culture chambers ( 24 wells, $8-\mu \mathrm{m}$ pore size; Corning). Briefly, upper inserts were coated with a thin layer of ECMatrix $(50 \mu \mathrm{l})$, including $10 \mathrm{mg} \mathrm{ml}^{-1}$ Matrigel (BD Biosciences), $0.2 \mathrm{mg} \mathrm{ml}^{-1}$ gelatin, $0.1 \mathrm{mg} \mathrm{ml}^{-1}$ fibronectin, or $0.2 \mathrm{mg} \mathrm{ml}^{-1}$ collagen I (all from Sigma-Aldrich, St. Louis, MO, USA), and allowed to set for $6 \mathrm{~h}$ at $37^{\circ} \mathrm{C}$. Then, $1.0 \times 10^{5} \mathrm{~A} 549$ cells were resuspended in $200 \mu \mathrm{l}$ of serum-free RPMI-1640 medium and the co-cultured supernatant (1:1), and seeded onto Matrigel. MAZ51 $(5 \mu \mathrm{M})$ was added in $200 \mu \mathrm{l}$ of serum-free RPMI-1640 medium and the co-cultured supernatant $(1: 1)$. RPMI-1640 medium (700 $\mu \mathrm{l})$ with $10 \%$ FCS was added to the lower chamber. After $24 \mathrm{~h}$ of incubation at $37^{\circ} \mathrm{C}$ in $5 \% \mathrm{CO}_{2}$, the invaded cells were fixed and stained with $0.05 \%$ crystal violet. Cells on the upper surface of the inner chamber were removed with cotton swabs. The invaded cells were counted in 10 different fields for each insert. The experiments were repeated three times.

Immunohistochemical (IHC) assay. The expression and distribution of VEGFR3 and Ki-67 in tissues were examined by IHC. The antihuman VEGFR3 antibody (1:100 dilution; Santa Cruz Biotechnology, USA) and the Ki-67 antibody (1:100 dilution; Wan Lei, China) were applied to detect their expression. Before the start of immunostaining, human and animal sections were deparaffinized in xylol (3x10 min) and dehydrated in decreasing concentrations of ethanol $(2 \times 100$, $1 \times 95,1 \times 90,1 \times 80$, and $1 \times 70 \%$ for 5 min each and $3 \times$ distilled water for $3 \mathrm{~min}$ each). Antigen retrieval was performed by boiling the sections for $10 \mathrm{~min}$ in $0.01 \mathrm{mM}$ citrate buffer ( $\mathrm{pH}$ 6.0). Thereafter, the sections were cooled down to room temperature (RT) and washed $2 \times 3$ min with PBS (pH 7.2-7.4), and then $3 \% \mathrm{H}_{2} \mathrm{O}_{2}$ was used for $10 \mathrm{~min}$ at RT to block endogenous peroxidase. Goat serum for closure was used to block non-specific binding. Primary antibodies were diluted in PBS and dropped dropwise to cover the sections. Then, the sections were incubated overnight at $4{ }^{\circ} \mathrm{C}$ in the refrigerator. The following day, the sections were washed three times for $5 \mathrm{~min}$ and then incubated for $30 \mathrm{~min}$ at $37^{\circ} \mathrm{C}$ with secondary antibodies diluted in the same buffer used for primary antibodies. After this incubation, the sections were washed $2 \times 5$ min with PBS and stained with DAB, which was followed by $2 \times 5$ min washes with distilled water. Then the sections were incubated for 2 min with hematoxylin staining solution and washed for 2 min with distilled water. In the next step, the human sections were treated with hydrochloric acid alcohol solution for $20 \mathrm{sec}$ and then washed with distilled water. The sections were treated with lithium carbonate for $5 \mathrm{~min}$ and then washed with distilled water. Finally, the sections were dehydrated in increasing concentrations of ethanol (1x70, 1x80, 1x90, 1x95, and $2 \times 100 \%$ for $2 \mathrm{~min}$ each) and xylol $(2 \times 2 \mathrm{~min})$.

Western blot assay. Co-cultured A549 cells [co-cultured media and RPMI-1640 media (1:1)] were lysed in buffer (50 mM Tris- $\mathrm{HCl}, \mathrm{pH} 8.0,100 \mathrm{mM} \mathrm{NaCl}, 0.1 \%$ SDS, $1 \%$ Triton $\mathrm{X}-100)$ containing protease and phosphatase inhibitors on ice. The proteins were quantitated by bicinchoninic acid (BCA) assay. Two hundred micrograms of proteins were subjected to SDS-PAGE gel and transferred to PVDF membranes. The membranes were blocked with $5 \%$ bovine serum albumin for $2 \mathrm{~h}$ at $37^{\circ} \mathrm{C}$ and then incubated with the respective primary antibody overnight at $4^{\circ} \mathrm{C}$, followed by incubation with the appropriate HRP-conjugated secondary antibody for $1 \mathrm{~h}$ at $37^{\circ} \mathrm{C}$. The blots were visualized with enhanced chemoluminescence (Millipore Corporation, Billerica, MA, USA) and the results were recorded according to the Bio-Rad electrophoresis documentation (Gel Doc 1000; Bio-Rad, USA) and Quantity One version 4.5.0. The antibodies used for western blot analysis include anti-VEGF-C (1:1,000 dilution) and anti-VEGFR3 (1:1,000 dilution) (both from Santa Cruz Biotechnology, Santa Cruz, CA, USA), anti-p-ERK1/2 and anti-ERK (1:1,000 dilution; Cell Signaling Technology, Danvers, MA, USA), anti- $\beta$-actin (1:1,000 dilution; ZSGB-Bio, Beijing, China), anti-p-JNK and anti-JNK (1:1,000 dilution; Cell Signaling Technology), anti-p-p38 and anti-p38 (1:300 dilution; Santa Cruz Biotechnology), anti-p53 and anti-PTEN (1:500 dilution; Abcam, UK), anti-BCL-2, and anti-MMP-2 (1:500 dilution; BoHai Co., Hebei, China).

Small interfering RNA transfection. All siRNA used in this study were purchased from Guangzhou Ribobio Co., Ltd. (China). The siRNA sequences used in this study were as follows: siRNA against p53 was: 5'-CCACUUGAUGGAGAG UAUUTT-3' (forward) and 5'-AAUACUCUCCAUCAAGUG GTT-3' (reverse); siRNA against PTEN was: 5'-GAGCGUGC AGAUAAUGACAdTdA-3' (forward) and 5'-dAdTCUCGCACGUCUAUUACUGU-3' (reverse). Cell transfection was performed using Lipofectamine 2000 (Thermo Fisher Scientific, Waltham, MA, USA) according to the manufacturer's instructions. The cells were seeded in free-antibiotic media and cultured for $24 \mathrm{~h}$ before siRNA transfection. Blank control, non-targeting control and the siRNA groups were set up. Then, the cells were mixed with Lipofectamine ${ }^{\mathrm{TM}} 2000$ (Thermo Fisher Scientific) and siRNA and then incubated in $5 \% \mathrm{CO}_{2}$ at $37^{\circ} \mathrm{C}$ for $6 \mathrm{~h}$, after which the media was changed to complete media and incubation was continued for $48 \mathrm{~h}$ before harvesting cellular RNAs. The efficacy of siRNA transfection was evaluated by semi-quantitative PCR.

Cell proliferation assay. A549 cells were seeded into 96-well plates at a density of $2 \times 10^{3}$ cells/well $(100 \mu \mathrm{l})$ and incubated in co-cultured media for $24 \mathrm{~h}$. The media was replaced with co-cultured media containing various concentrations of MAZ51 and with co-cultured media without MAZ51 serving as the negative control. After incubation for $24 \mathrm{~h}, 10 \mu \mathrm{l}$ of MTT reagent ( $5 \mathrm{mg} / \mathrm{ml}$; Progema, Madison, WI, USA) was added and incubation followed for $4 \mathrm{~h}$ at $37^{\circ} \mathrm{C}$. Then $100 \mu \mathrm{l}$ dimethyl sulfoxide was added to dissolve the formazan product for $10 \mathrm{~min}$ in the dark at RT and the absorbance at $492 \mathrm{~nm}$ was recorded.

Apoptosis and cell cycle. The co-cultured A549 cells [diluted by co-cultured media and RPMI-1640 media (1:1)] at $60 \%$ confluency were treated with either DMSO alone or $5 \mu \mathrm{M}$ of MAZ51. After $24 \mathrm{~h}$ of treatment, the cells were harvested and washed three times with PBS, followed by labeling with Annexin V-PI according to the Annexin V-FITC apoptosis detection kit protocol (BD Biosciences, San Jose, CA, USA) before analysis by flow cytometry within $1 \mathrm{~h}$. For the detection of the cell cycle, the co-cultured A549 cells treated were fixed 

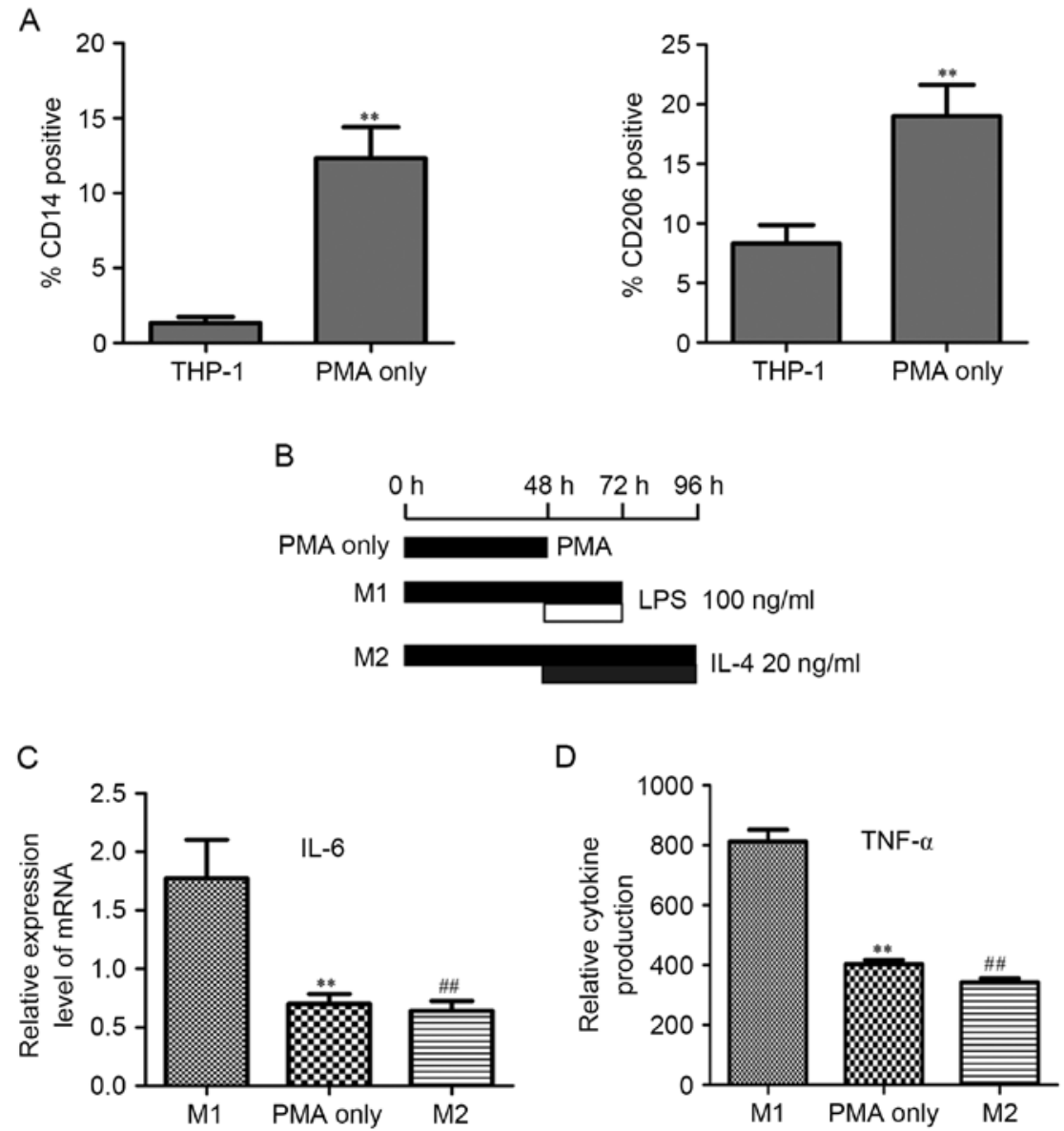

Figure 1. PMA treatment differentiates THP-1 cells to M2 macrophages. (A) THP-1 cells treated with $320 \mathrm{nM}$ PMA for $48 \mathrm{~h}$ exhibited significant induction for CD14 (marker for macrophage differentiation) and CD206 (marker for M2 macrophages differentiation). ${ }^{* *} \mathrm{P}<0.01$. (B) After treatment with $320 \mathrm{nM}$ PMA for 48 h, THP-1 cells differentiated to the 'PMA-treated THP-1 macrophages' (labeled 'PMA only'). 'M1-polarized THP-1 macrophages' (M1) were obtained by treating THP-1 cells with PMA for $72 \mathrm{~h}$ and polarizing them with Th1 cytokine (100 ng ml-1 LPS) for $24 \mathrm{~h}$ (added $48 \mathrm{~h}$ after PMA). For the 'M2-polarized THP-1 macrophages' (M2), THP-1 cells were treated with PMA for $48 \mathrm{~h}$, then cultured with PMA plus $20 \mathrm{ng} \mathrm{ml}^{-1}$ IL-4 for another $48 \mathrm{~h}$. (C) PMA-treated THP-1 macrophages (PMA only) and M2-polarized THP-1 macrophages (M2) both had significantly lower mRNA level of IL-6, compared with that of M1-polarized THP-1 macrophages (M1). (D) PMA-treated THP-1 macrophages (PMA only) and M2-polarized THP-1 macrophages (M2) both had significantly lower cytokine level of TNF- $\alpha$ compared with that of M1-polarized THP-1 macrophages (M1). All P<0.01; ${ }^{* *}$ PMA only vs. M1; ${ }^{\# \#}$ M2 vs. M1. TNF- $\alpha$, tumor necrosis factor- $\alpha$.

at a concentration of $1 \times 10^{6}$ cells $/ \mathrm{ml}$ with $75 \%$ cold ethanol overnight at $4^{\circ} \mathrm{C}$. The cell cycle distribution was then analyzed by flow cytometry using the fluorescence-activated cell sorting (FACS) analysis core services of the Chongqing Medical University (Chongqing, China).

Tumor sphere assays. Eight hundred A549 cells in $2 \mathrm{ml}$ of RPMI-1640 medium (Hyclone, USA) were seeded in 6-well plates (Corning, Acton, MA, USA). After $24 \mathrm{~h}$, the cells were treated with co-cultured media and RPMI-1640 media (1:1) alone (control) or MAZ51 in co-cultured media and RPMI-1640 media (1:1) at a $5 \mu \mathrm{M}$ concentration. Following a 5-day incubation period at $37^{\circ} \mathrm{C}$ in a humidified atmosphere comprised of $5 \% \mathrm{CO}_{2}$ the cells were stained with crystal violet and the clones were counted. The experiment was repeated three times.

Cytotoxic assays. A549 cells were cultured in RPMI-1640 and co-cultured media (1:1) for $24 \mathrm{~h}$ and then treated with indicated sequences of the VEGFR3 inhibitor MAZ51 and the chemotherapeutic drug. The A549 cell replicates were treated with i) DMSO (control); ii) MAZ51 (5 $\mu \mathrm{M})$ daily for 1 day; iii) doxorubicin ( $3 \mu \mathrm{M})$ for 1 day; iv) doxorubicin and MAZ51 concurrent for 1 day; v) doxorubicin for 1 day followed by MAZ51 for 1 day; and vi) MAZ51 for 1 day followed by doxorubicin for 1 day. The cell viability was then evaluated using the apoptosis experiment. Each assay was repeated at least three times.

Animal studies. Four- to six-week-old BALB/c-nu mice were purchased from the Animal Experimental Center of the Medical University of Chongqing. All experiments were performed with the approval of the Medical University of Chongqing Committee on the Use and Care of Animals. The tumors were initiated with $1 \times 10^{6}$ A549 cells and M2 macrophage cells (3:1) combined with $100 \mu \mathrm{l}$ of PBS, and then implanted subcutaneously ( $\mathrm{n}=4$ tumors per treatment group). One week after tumor inoculation, the mice were treated through intraperitoneal injection with i) control DMSO; or ii) MAZ51 and doxorubicin ( 6 and $5 \mathrm{mg} / \mathrm{kg}$, respectively) in DMSO. The tumor growth was assessed using calipers, and the tumor volume was calculated by the following modified ellipsoid formula: $(\mathrm{L} x \mathrm{~W} \times \mathrm{W}) / 2$. 
A

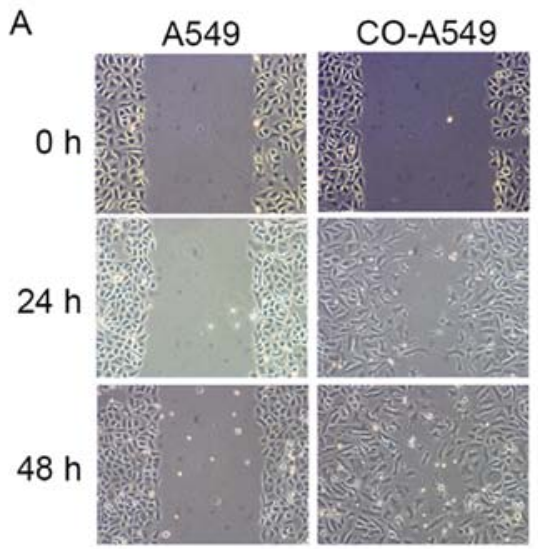

B

$24 \mathrm{~h}$

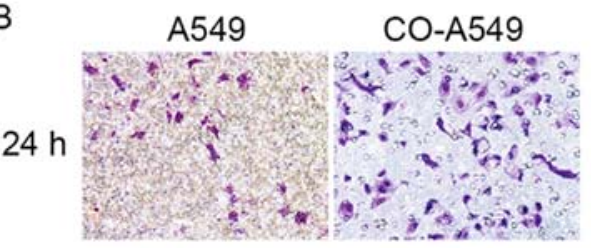

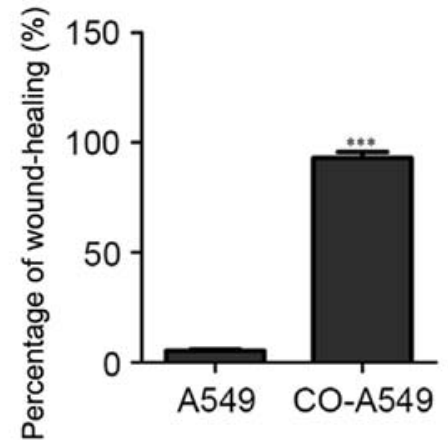

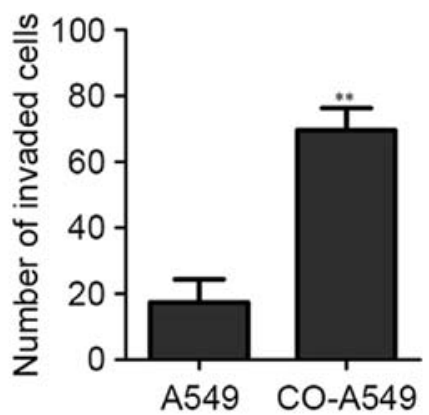

Figure 2. M2 macrophages induce migration and invasion of A549 cells. (A) Lung adenocarcinoma A549 cell line was treated with the co-cultured supernatant of M2 macrophages and A549 cells (CO-A549) and compared with A549 cells alone. Migration of A549 cells was assessed by wound-healing assay. Bar charts represent the mean percentage (\%) of cell migration, \pm SD. A P-value was generated using a two sided t-test to A549 cells alone. ${ }^{* * * *} \mathrm{P}<0.001$. (B) The lung adenocarcinoma A549 cell line was treated with the co-cultured supernatant of M2 macrophages and A549 cells (CO-A549) and compared with A549 cells alone. The invasion potential of A549 cells was detected by Matrigel invasion assay. Data are expressed as the mean number of invading cells per field (average of 10 fields per filter). ${ }^{* *} \mathrm{P}<0.01$.

Statistical analyses. The results represent the average of three independent experiments and the data are presented as the mean \pm standard deviation. All the statistical analyses were performed using GraphPad Prism 5 (GraphPad Software, La Jolla, CA, USA). Statistical significance was determined using Student's paired t-test, and $\mathrm{P}<0.05$ was considered to indicate a statistically significant difference.

\section{Results}

PMA treatment differentiates THP-1 cells to M2 macrophages. The THP-1 cells are widely used as models for macrophage differentiation. After treatment with $320 \mathrm{nM}$ PMA for $48 \mathrm{~h}$, THP-1 cells quickly stopped proliferating, became attached, and differentiated to macrophages (CD14 positive) (Fig. 1A). The M2-type macrophage surface marker CD206 was significantly increased compared to the PMA-treated THP-1 cells (Fig. 1A).

Macrophages have a tremendous degree of functional plasticity. They can alter their functional properties (from M1 to M2 or M2 to M1) repeatedly depending on the specific cytokine (Th1 or Th2) in the tumor microenvironment (11).M2-polarized macrophages would be polarized to M1 and M1-polarized macrophages would be polarized to M2 depending on the Th1 or Th2 cytokines to which they were exposed to, respectively. We assumed that PMA-treated THP-1 macrophages were M2 macrophages. When Th1 cytokine (LPS) was used to treat PMA-induced THP-1 macrophages, they were polarized to M1 macrophages and had an M1 macrophage expression. When Th2 cytokine (IL-4) was used to treat PMA-induced
THP-1 macrophages, they had an M2 macrophage expression. On the basis of this, we generated M1-polarized THP-1 macrophages by treating THP-1 cells with PMA for $72 \mathrm{~h}$ and polarizing them with Th1 cytokine (100 ng/ml $\left.\mathrm{l}^{-1} \mathrm{LPS}\right)$ for $24 \mathrm{~h}$ (added $48 \mathrm{~h}$ after PMA). M2-polarized THP-1 macrophages were obtained from THP-1 cells treated with PMA for $96 \mathrm{~h}$ and polarizing them with Th2 cytokine $\left(20 \mathrm{ng} / \mathrm{ml}^{-1} \mathrm{IL}-4\right)$ for $48 \mathrm{~h}$ (added $48 \mathrm{~h}$ after PMA; scheme shown in Fig. 1B). The mRNA levels of the PMA-treated, M1-polarized and M2-polarized THP-1 macrophages were compared. A similar trend was observed in the mRNA of the PMA-treated and M2-polarized THP-1 macrophages. Their mRNA level of IL-6 was significantly lower to that of the M1-polarized THP-1 macrophages (Fig. 1C). The cytokine level of the TNF- $\alpha$ in the PMA-treated, M1-polarized and M2-polarized THP-1 macrophages shared the same tendency as the IL-6 mRNA level (Fig. 1D). Taking into consideration the mRNA level, cytokine profile and surface markers, PMA-treated THP-1 macrophages had an M2 functional property.

M2 macrophages induce migration and invasion of A549 cells. We then used the co-cultured supernatant of the M2 macrophages and A549 cells to treat A549 cells. A549 cells (3.0x $10^{5}$ cells/well) were seeded into a 6 -well plate. When the cell density reached $80 \%$ the cell monolayers were then damaged with a micropipette to create a linear wound $2 \mathrm{~mm}$ in width. The co-cultured supernatant (diluted 1:5) was added and the cells were incubated for 24 and $48 \mathrm{~h}$ at $37^{\circ} \mathrm{C}$ in a $5 \%$ $\mathrm{CO}_{2}$ incubator. The untreated A549 cells were used as a negative control. The co-cultured A549 cells exhibited an increased 

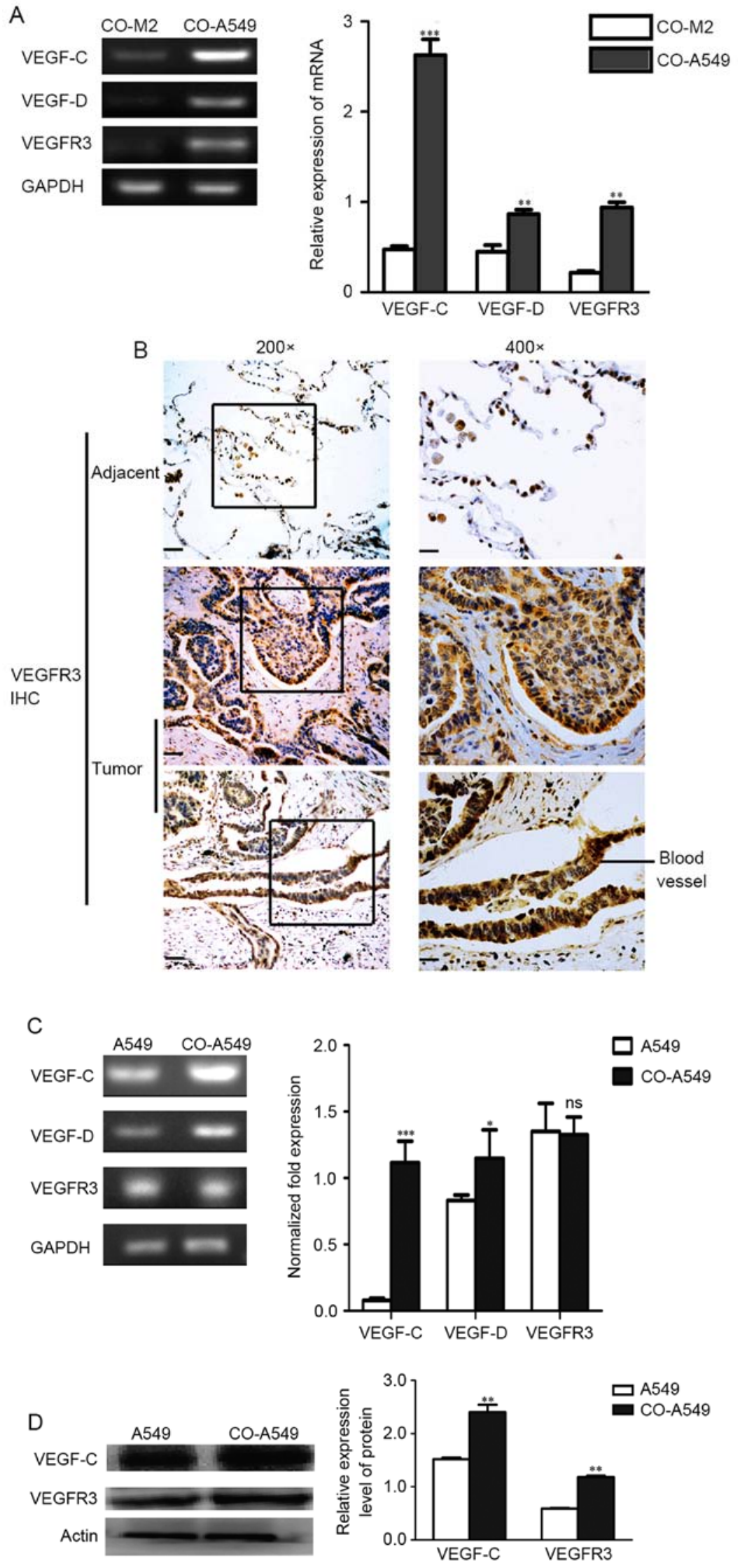

Figure 3. Expression levels of VEGF-C, VEGF-D, and VEGFR3 in the lung adenocarcinoma A549 cell line. (A) RT-PCR evaluations of VEGF-C mRNA, VEGF-D mRNA and VEGFR3 mRNA in co-cultured M2 macrophages (CO-M2) and co-cultured A549 cells (CO-A549) are presented. (B) IHC demonstrating that VEGFR3 expression in human lung adenocarcinoma is primarily found in tumor cells than in stromal and adjacent cells. VEGFR3 expression was also found in blood vessels. Scale bars, $20 \mu \mathrm{m}$. (C) Semi-quantitative RT-PCR and qRT-PCR evaluation of VEGF-C mRNA, VEGF-D mRNA and VEGFR3 mRNA are presented. The co-cultured A549 cells (CO-A549) had a higher expression level of VEGF-C mRNA and VEGF-D mRNA than that of the A549 cells alone. (D) Western blot analysis confirmed a high protein expression of VEGF-C and VEGFR3 in CO-A549 cells. ${ }^{*} \mathrm{P}<0.05,{ }^{* *} \mathrm{P}<0.01,{ }^{* * * *} \mathrm{P}<0.001$. VEGFR, vascular endothelial growth factor receptor; IHC, immunohistochemistry. 

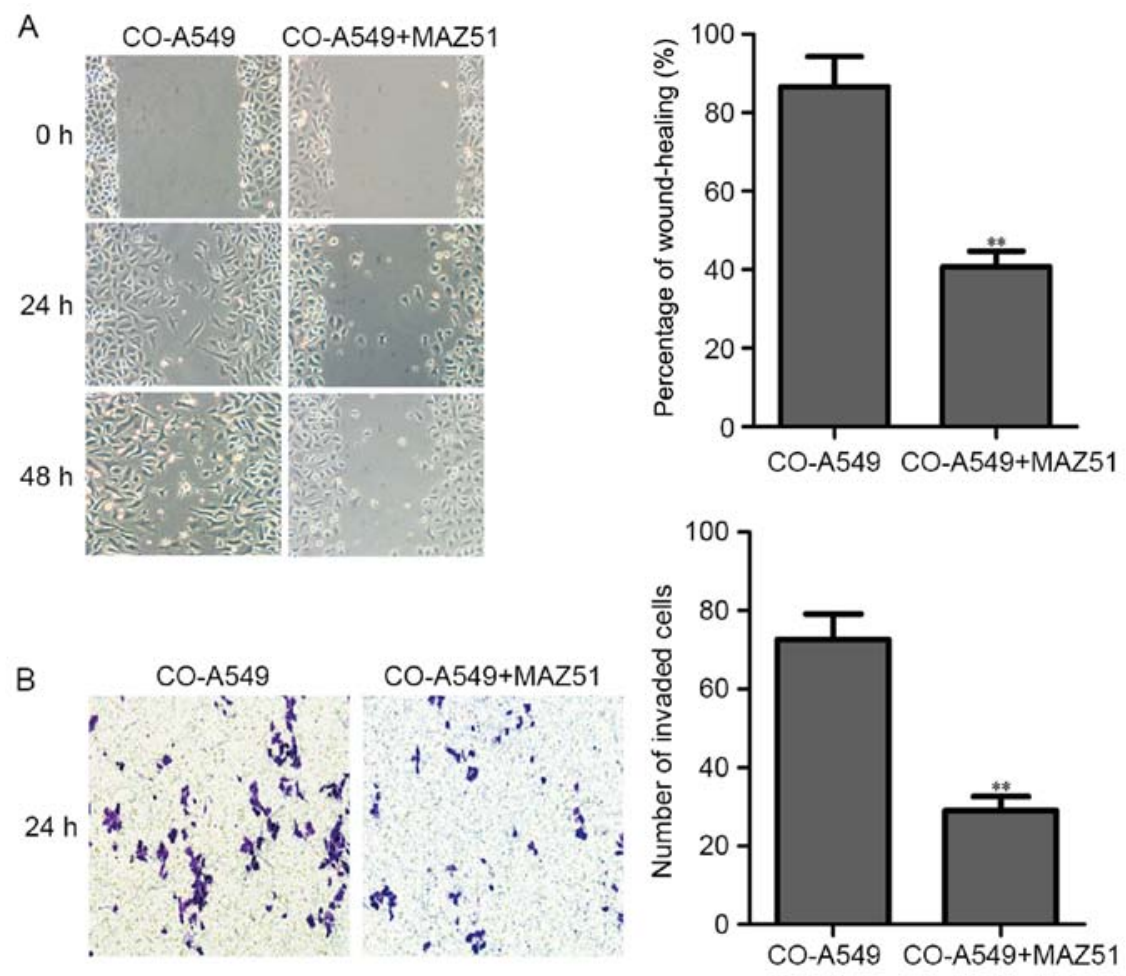

Figure 4. VEGFR3 inhibition decreases migration and invasion of co-cultured A549 cells. (A) The co-cultured lung adenocarcinoma A549 cell line was treated with the VEGFR3 inhibitor (MAZ51) and compared to co-cultured A549 cells alone. The migration of co-cultured A549 cells treated with the VEGFR3 inhibitor (MAZ51) was assessed by wound-healing assay. Bar charts represent the mean percentage (\%) of cell migration \pm SD. A P-value was generated using a two sided t-test to co-cultured A549 cells alone. ${ }^{* *} \mathrm{P}<0.01$. (B) The co-cultured lung adenocarcinoma A549 cell line was treated with the VEGFR3 inhibitor (MAZ51) and compared to co-cultured A549 cells alone. The invasion potential of co-cultured A549 cells was detected by Matrigel invasion assay. Data are expressed as the mean number of invading cells per field (average of 10 fields per filter). ${ }^{* *} \mathrm{P}<0.01$. VEGFR3, vascular endothelial growth factor receptor 3.

percentage of cell migration (Fig. 2A). For the invasion assay, A549 cells $\left(0.2 \times 10^{5}\right.$ cells in a 6 -well plate) were seeded into Matrigel-coated invasion chambers ( 24 wells, $8-\mu \mathrm{m}$ pore size). After $24 \mathrm{~h}, \mathrm{~A} 549$ cells were fixed, stained with crystal violet, and counted for invaded cells. A549 cells that had been treated with the co-cultured supernatant of the M2 macrophages and A549 cells exhibited an increased number of invaded cells (Fig. 2B).

Expression of VEGF-C, VEGF-D, and VEGFR3 in tumor cells. We evaluated the expression levels of VEGF-C, VEGF-D, and their primary receptor, VEGFR3, in co-cultured M2 macrophages and co-cultured A549 cells. RT-PCR evaluation of VEGF-C, VEGF-D and VEGFR3 expression demonstrated that they were mainly expressed in the co-cultured tumor cells compared to the co-cultured M2 macrophages (Fig. 3A). In addition, semi-quantitative RT-PCR and quantitative real-time RT-PCR (qRT-PCR) demonstrated that M2 macrophages promoted the expression of VEGF-C, VEGF-D and VEGFR3 in A549 cells (Fig. 3C). Western blot analysis confirmed the higher protein levels of VEGF-C and VEGFR3 in the co-cultured A549 cells compared to A549 cells alone (Fig. 3D). Immunohistochemistry performed on primary human lung adenocarcinoma cells confirmed that VEGFR3 was mainly expressed in tumor cells than in stromal cells (Fig. 3B). In adjacent cells, VEGFR3 was primarily expressed in tumor cells, with no expression exhibited in adjacent cells (Fig. 3B).

VEGFR3 inhibition decreases migration and invasion of co-cultured A549 cells. The A549 cells (3.0x10 cells/well) were seeded into a 6-well plate with the co-cultured supernatant of M2 macrophages and A549 cells (diluted 1:5). When the cell density reached $80 \%$, the cell monolayers were then damaged with a micropipette to create a linear wound $2 \mathrm{~mm}$ in width. The VEGFR3 inhibitor (MAZ51) was then added $(5 \mu \mathrm{M})$. Subsequently, the cells were incubated for 24 and $48 \mathrm{~h}$ at $37^{\circ} \mathrm{C}$ in a $5 \% \mathrm{CO}_{2}$ incubator. The co-cultured A549 cells without MAZ51 were used as a negative control. The co-cultured A549 cells with MAZ51 (5 $\mu \mathrm{M})$ revealed a decreased percentage of cell migration (Fig. 4A).

For the invasion assay, the co-cultured A549 cells $\left(0.2 \times 10^{5}\right.$ cells) with the VEGFR3 inhibitor (MAZ51, $5 \mu \mathrm{M}$, in a 6 -well plate) were seeded into Matrigel-coated invasion chambers ( 24 wells, $8-\mu \mathrm{m}$ pore size). After $24 \mathrm{~h}$, the co-cultured A549 cells were fixed, stained with crystal violet, and counted for invaded cells. The co-cultured A549 cells without MAZ51 were used as a negative control. The co-cultured A549 cells with MAZ51 $(5 \mu \mathrm{M})$ revealed a decreased number of invaded cells (Fig. 4B).

VEGFR3 inhibition results in tumor cell growth arrest. We next assessed the impact of the VEGFR3 inhibitor MAZ51 on co-cultured A549 cell growth. Co-cultured A549 cells demonstrated a dose-dependent decrease in cell growth, with an $\mathrm{IC}_{50}$ of approximately $2.5 \mu \mathrm{M}$, and most of the cells had growth arrest at $5 \mu \mathrm{M}$ (Fig. 5A). In addition, Annexin V/PI analysis demonstrated that MAZ51 induced apoptosis of co-cultured A549 cells (Fig. 5B). To further confirm the impact of the VEGFR3 inhibition on tumor cell growth, we performed tumor sphere 
A

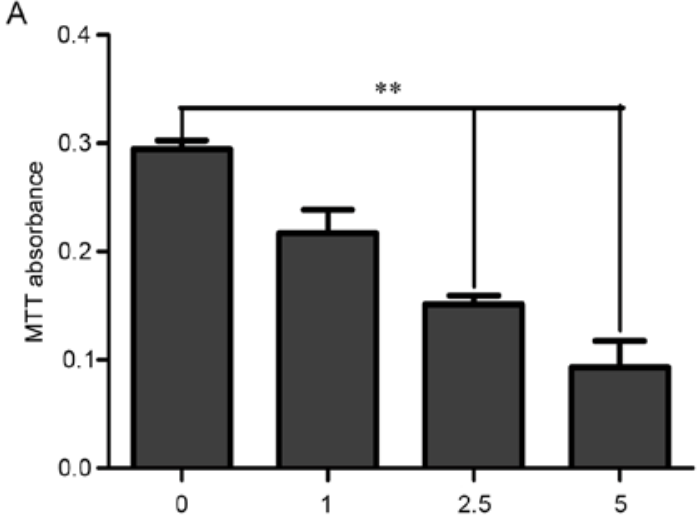

C

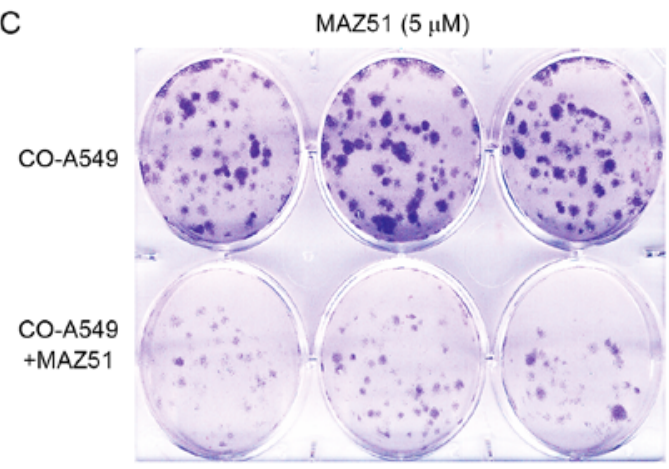

B
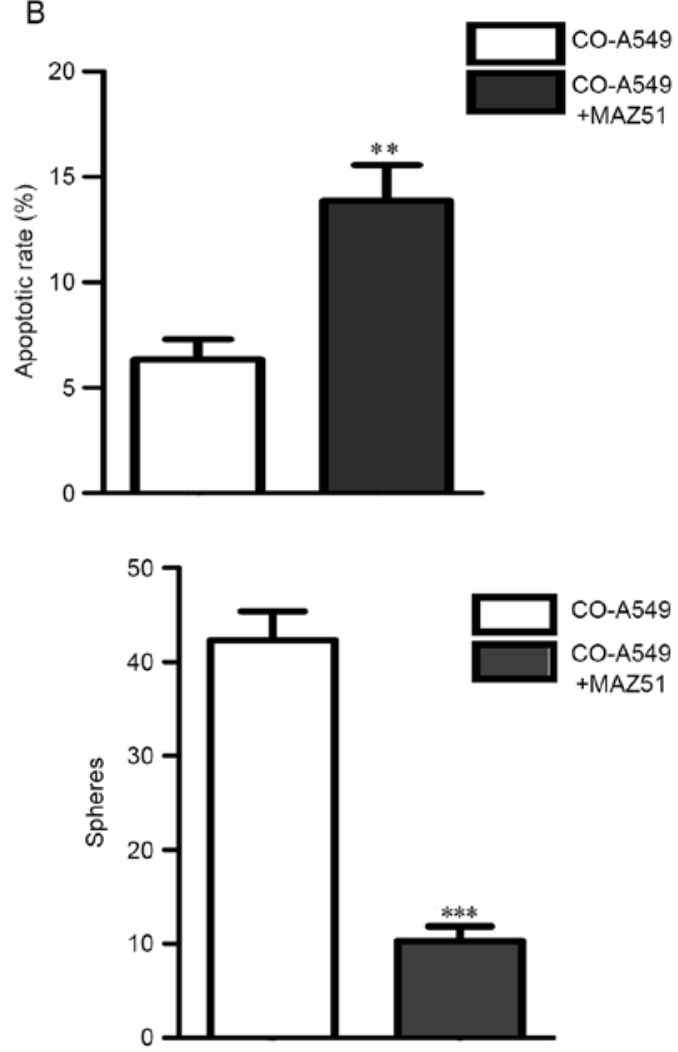

$\mathrm{D}$

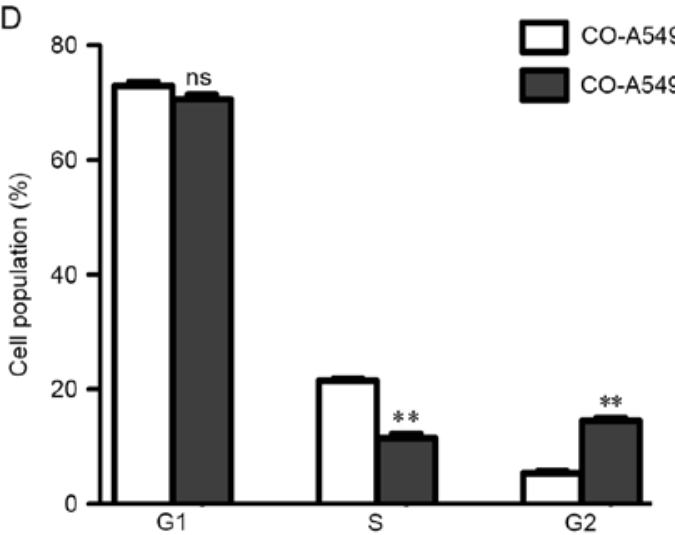

Figure 5. VEGFR3 inhibition results in co-cultured A549 cell growth arrest. (A) Co-cultured A549 cell growth ability after treatment with the indicated doses of MAZ51 is presented by MTT assay. (B) The apoptotic rate is evaluated after treatment with MAZ51 (5 $\mu \mathrm{M})$ for $24 \mathrm{~h}$ by flow cytometry. (C) Quantification and representative images of tumor spheres formed in the presence of MAZ51 $(5 \mu \mathrm{M})$ are shown. (D) The cell cycle was evaluated after treatment with MAZ51 $(5 \mu \mathrm{M})$. MAZ51 decreased the number of cells in the $\mathrm{S}$ phase, with a concurrent increase in the number of cells in the G2 phase. ${ }^{* *} \mathrm{P}<0.01,{ }^{* * * *} \mathrm{P}<0.001$. VEGFR3, vascular endothelial growth factor receptor 3.

assays on tumor cells. Similar to that observed with the cell line data, $5 \mu \mathrm{M}$ doses of MAZ51 were associated with nearly complete inhibition of tumor sphere formation (Fig. 5C). The cell cycle analysis with MAZ51 demonstrated a significant decrease in the number of cells in the $S$ phase, with a concurrent increase in the number of cells in the G2 phase (Fig. 5D). Collectively, these data indicated that MAZ51 induced growth arrest and induced apoptosis of lung adenocarcinoma A549 cells.

Impact of VEGFR3 inhibition on cell signaling. We next evaluated downstream targets of VEGFR3 inhibition. Western blot analysis of phosphoproteins in co-cultured A549 cells demonstrated that MAZ51 treatment of cells was associated with a decreased p-ERK expression level (Fig. 6A). However, VEGFR3 inhibition was not associated with the expression levels of p-JNK and p-p38 (Fig. 6A).

Given that VEGFR3 inhibition was associated with cell cycle arrest and apoptosis and that proteins p53 and PTEN are known to regulate the cell cycle and apoptosis, we next specifically evaluated the impact of VEGFR3 inhibition on p53 and PTEN protein expression. Western blot analysis confirmed that MAZ51 treatment of co-cultured A549 cells increased the protein expression levels of p53 and PTEN (Fig. 6B). With MAZ51 treatment, we also observed decreased levels of BCL-2 and MMP-2 in the co-cultured A549 cells (Fig. 6B). 
A

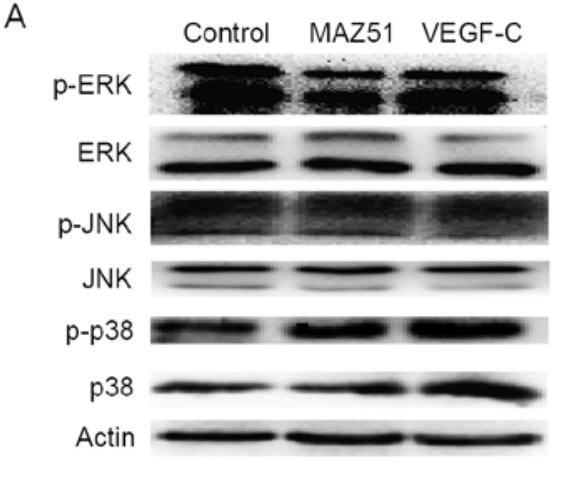

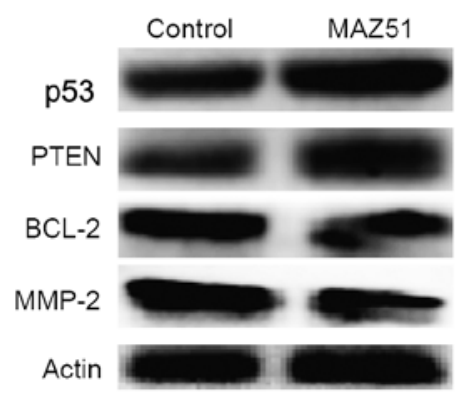

C

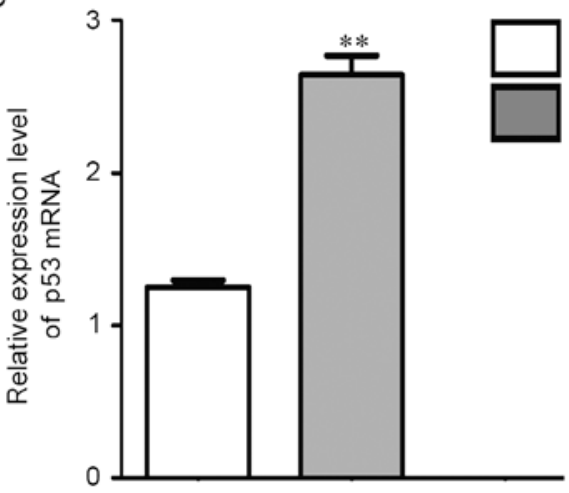

D

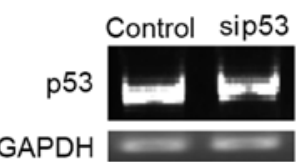

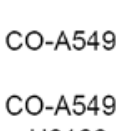

$+\cup 0126$

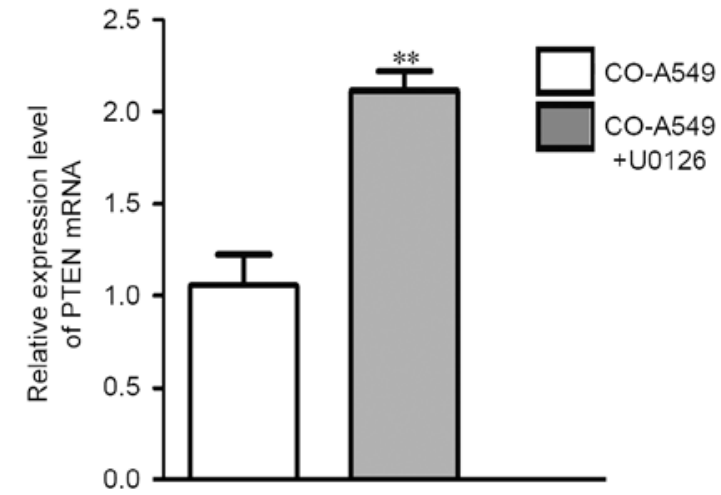

GAPDH
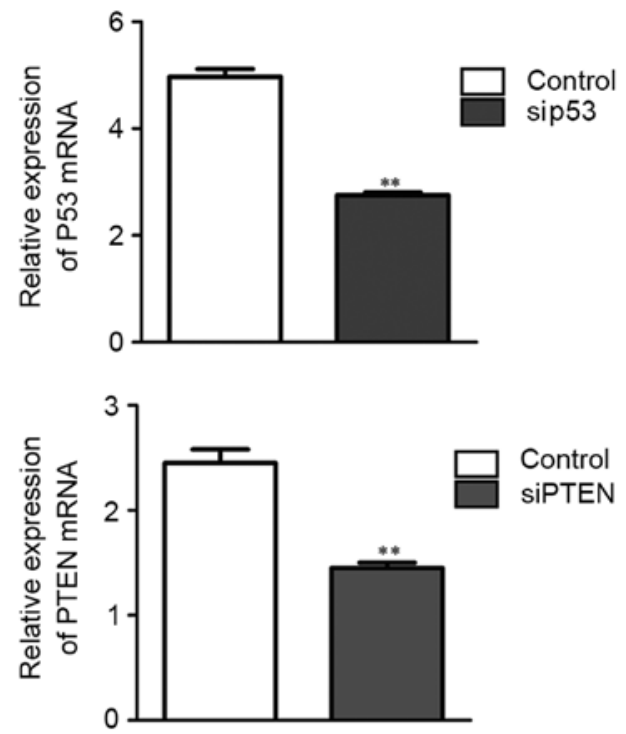

E

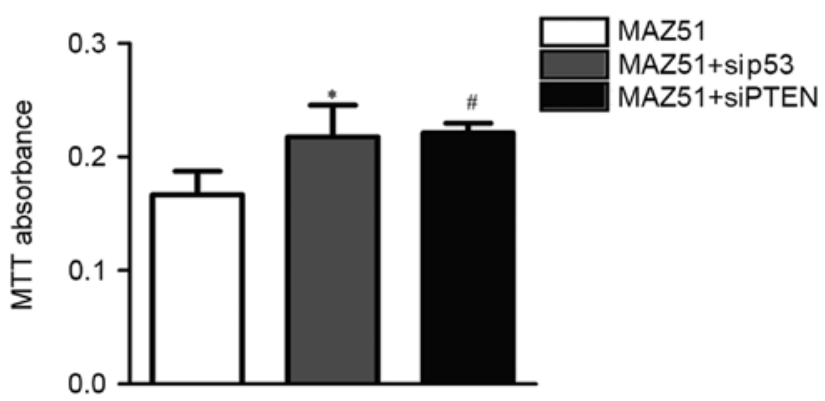

Figure 6. VEGFR3 inhibition improves p53 and PTEN protein expression through p-ERK. (A) Western blot analysis of phosphoproteins, control, MAZ51 and VEGF-C-treated co-cultured A549 cells revealed that MAZ51 treatment was associated with decreased p-ERK. (B) Western blot anlaysis demonstrating that MAZ51 treatment is associated with upregulated proteins p53 and PTEN in co-cultured A549 cells. (C) MEK1 inhibition (U0126) is associated with upregulation of p53 and PTEN mRNA levels. ${ }^{* *} \mathrm{P}<0.01$. (D) The expression levels of p53 and PTEN mRNA after treatments of siRNA-p53 (sip53) and siRNA-PTEN (siPTEN). ${ }^{* *} \mathrm{P}<0.01$. (E) The proliferation was evaluated after treatment with siRNA in co-cultured A549 cells by MTT assay. ${ }^{*} \mathrm{P}<0.05,{ }^{*} \mathrm{P}<0.05$. VEGFR3, vascular endothelial growth factor receptor 3; p-ERK, p-extracellular signal-regulated kinase; MEK1, mitogen-activated protein kinase kinase 1. 
A

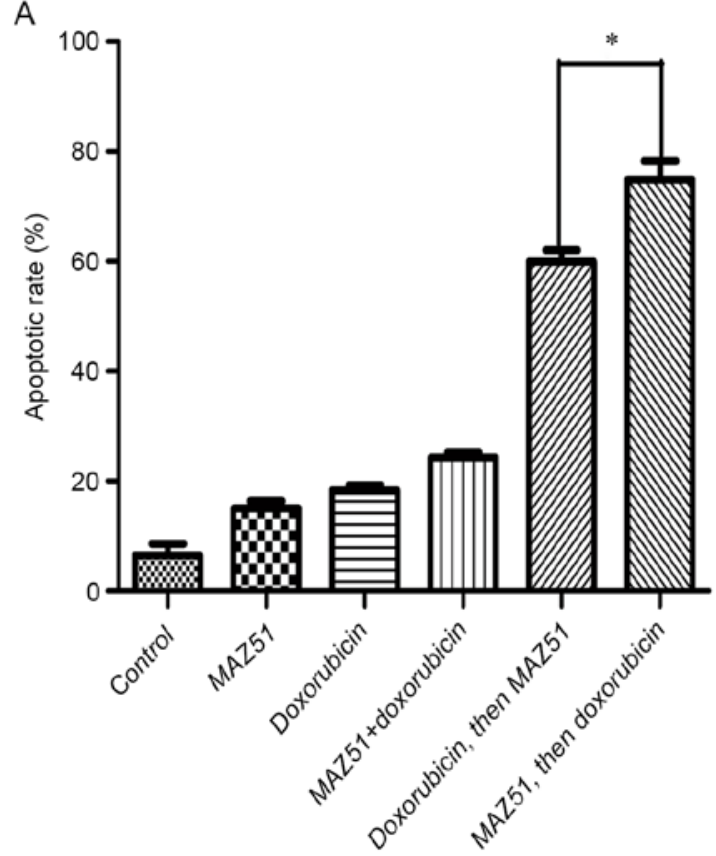

C

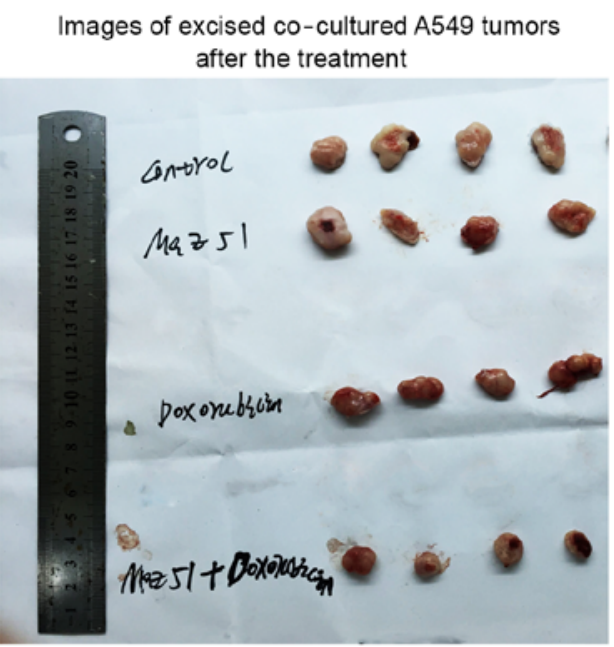

B

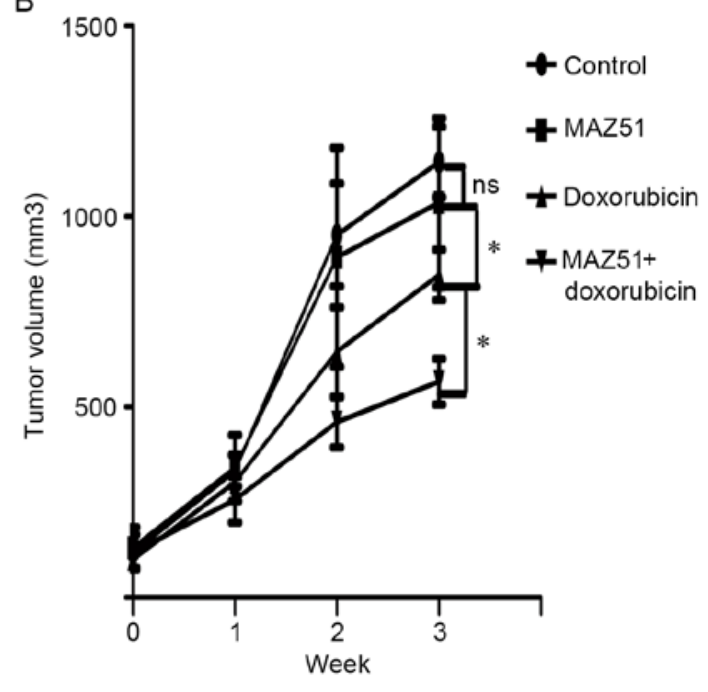

D

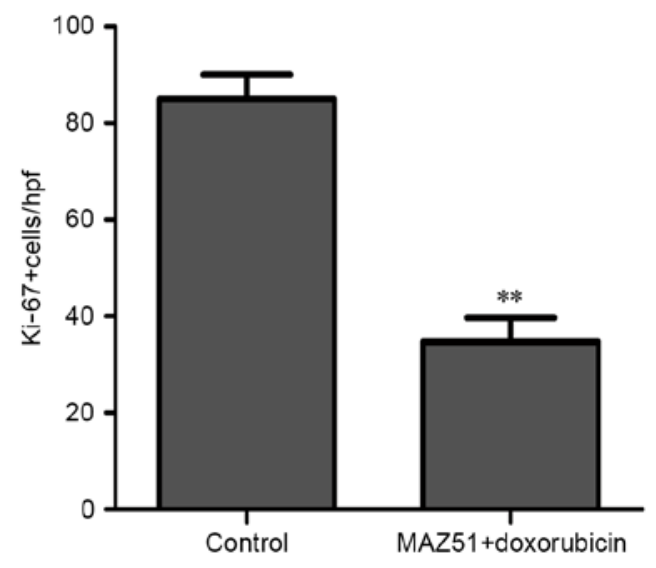

Figure 7. VEGFR3 inhibition enhances chemosensitivity. (A) The apoptotic rate of co-cultured A549 cells treated with MAZ51 only, doxorubicin chemotherapy only, MAZ51 and doxorubicin concurrently, doxorubicin followed by MAZ51, or MAZ51 followed by doxorubicin is presented. (B) Tumor growth curves for co-cultured A549 cells treated with MAZ51 only, doxorubicin chemotherapy only, MAZ51 and doxorubicin concurrently. (C) Images of excised A549 tumors of different drug delivery strategies in the treatment of co-cultured A549 human lung adenocarcinoma cells implanted in athymic mice. (D) Quantification of Ki-67 in the control and Maz51 + doxorubicin-treated co-cultured A549 tumors are presented. All ${ }^{*} \mathrm{P}<0.05,{ }^{* *} \mathrm{P}<0.01$. VEGFR3, vascular endothelial growth factor receptor 3 .

To determine if phosphorylation of ERK played a central role in VEGFR3 inhibition-mediated promotion of p53 and PTEN protein expression, we treated co-cultured A549 cells with the mitogen-activated protein kinase kinase 1 (MEK1) inhibitor U0126 and assessed the p53 and PTEN mRNA levels. MEK inhibition increased both the p53 and PTEN mRNA expression levels (Fig. 6C).

To confirm the important role of p53 and PTEN upregulation in MAZ51-mediated growth arrest, we treated co-cultured A549 cells with and without siRNA-p53 and siRNA-PTEN (Fig. 6D). Co-cultured A549 cells without siRNA-p53 and siRNA-PTEN were less sensitive to MAZ51 treatment in tumor cell proliferation than those with siRNA-p53 and siRNA-PTEN (Fig. 6E).
VEGFR3 inhibition enhances chemosensitivity. Increased p53 and PTEN functions in patients are associated with increased chemosensitivity and a significantly improved outcome in patients with lung adenocarcinoma. We therefore assessed the impact of MAZ51 on the chemotherapy response of lung adenocarcinoma cells. We treated co-cultured A549 cells with MAZ51 before, concurrently, or after doxorubicin treatment. Pretreatment with MAZ51 followed by doxorubicin was the most effective means to delay tumor growth in vitro (Fig. $7 \mathrm{~A})$.

We next assessed the impact of MAZ51 treatment on tumor growth in vivo, in the co-cultured A549 cells. Single-agent MAZ51 treatment exhibited no response on tumor growth (Fig. 7B). We then assessed the impact of MAZ51 in 
combination with doxorubicin chemotherapy on co-cultured A549 cells. The results revealed a significant decrease of tumor growth in the co-cultured A549 cells (Fig. 7B and C) compared to doxorubicin therapy alone. These data revealed that MAZ51 enhanced the chemosensitivity of doxorubicin in lung adenocarcinoma cells. Evaluation of MAZ51 and doxorubicin-treated tumors demonstrated a significant decrease in Ki-67 (Fig. 7D).

\section{Discussion}

The present study indicates a critical role for VEGFR3 regulation of lung adenocarcinoma cell protein expression. VEGFR3 blockade resulted in the upregulation of both p53 and PTEN proteins, leading to chemosensitization. The primary source of VEGFR3 in the tumor microenvironment is lung adenocarcinoma cells.

These studies indicate another critical role for tumor-associated macrophages in the tumor microenvironment. Populations of tumor-associated macrophages, defined by the expression of various molecules (high CD206; low TNF- $\alpha$ and IL-6), have been reported to promote angiogenesis and suppress antitumor immunity $(29,30)$. In addition, tumorassociated macrophages have been linked with increased rates of tumor metastasis and establishment of a metastatic niche (31). We found that tumor-associated macrophages induced migration and invasion of A549 cells, meanwhile, tumor-associated macrophages promoted the expression of VEGF-C and VEGFR3 in A549 cells, which are consistent with previous studies that tumor-associated macrophages can induce high levels of VEGFR3 to produce robust but aberrant lymphangiogenesis $(32,33)$. Our studies indicate that VEGFR3, in addition to its well-known effects on lymphangiogenesis, has direct effects on the cancer cell.

We found that inhibition of VEGFR3 in A549 cells markedly restricted tumor cell growth. In addition, the migration and invasion of A549 cells in the tumor microenvironment were markedly restricted. In A549 cells, MAZ51 treatment-associated growth restriction was linked to a decrease in p-ERK, MMP-2, BCL-2 and an upregulation of p53 and PTEN. Treatment with a MEK inhibitor upregulated the expression of $\mathrm{p} 53$ and PTEN, suggesting that signaling from VEGFR3 through p-ERK regulates p53 and PTEN expression. Demonstrating a critical role for the p53 and PTEN genes, cells with siRNA-p53 and siRNA-PTEN were less sensitive to VEGFR3-inhibitor therapy.

With VEGFR3-inhibitor therapy, we observed increased chemosensitivity in vitro and in vivo. This was initially somewhat surprising given the observation that VEGFR3 inhibition induced cell cycle arrest. The non-specific cell cycle DNA-damaging chemotherapies such as doxorubicin are used to treat lung cancer. However, chemosensitization was greatest when cells were treated in sequence (VEGFR3 inhibition, followed by doxorubicin therapy in vitro), rather than concurrently. From the animal experiments, the VEGFR3 inhibitor improved chemosensitization significantly. Thus, VEGFR3 inhibition induced cellular arrest, and then when cells resumed proliferation after withdrawal of the VEGFR3 inhibitor, chemotherapy then killed the cells as they entered the cell cycle. Killing was increased in the presence of the p53 and PTEN genes.
Our findings have important clinical implications. In lung adenocarcinoma, patients with p53 and PTEN deficiencies have been reported to have a worse clinical outcome (34-38). This is presumed to be due to decreased sensitivity to chemotherapy. Indeed, when p53- and PTEN-deficient tumors become sensitivite to doxorubicin therapy, improved p53 and PTEN expression has been observed (39-43). Our studies indicate that VEGFR3 inhibition may represent a therapeutic means to upregulate p53 and PTEN expression in tumors, thus making them mimic p53- and PTEN-enhanced tumors. There is a great improvement in the overall survival rate of patients with p53- and PTEN-enhanced expression over p53- and PTEN-deficient patients with lung cancer. This simple intervention could markedly improve the outcome of these patients. Furthermore, for those patients who develop chemotherapy-resistant disease, it is possible that VEGFR3 inhibition could reverse this phenomenon thus improving the progression-free and overall survival.

Preclinical evidence supports VEGFR3 as a clinical target. VEGFR3 inhibitors have been found to both inhibit angiogenesis/lymphangiogenic activities and decrease metastases $(18,44,45)$. Notably, a soluble version of VEGFR3 has been identified (46). Several studies have now used VEGFR3 as a 'VEGF-C Trap' and reported a significant decrease in lymphangiogenesis and tumor metastases $(28,47,48)$.

Clinical evidence also supports a potentially meaningful role for VEGFR3 inhibitors. Recent studies revealed a 3.7-month progression-free survival for the VEGFR2 and VEGFR3 inhibitor regorafenib (49). This is significantly better than the 1.8-month progression-free survival advantage for the placebo cohort. We speculate that this effect could be due to the significant anti-VEGFR3 inhibitory action of regorafenib. Our data revealed that use of the VEGFR3 inhibitor (MAZ51) before or concurrently with chemotherapy markedly enhanced response rates in vitro and in vivo, respectively. Our results demonstrated that this treatment would significantly benefit the experimental arm. If this or other trials with VEGFR3 inhibitors reveal a significant clinical benefit compared to standard therapy of targeting the VEGF/VEGFR2 pathway, VEGFR3 expression on cancer cells could be an important biomarker of patient response.

Our present study was limited in that it was not performed with a clinically available compound. Unlike the compounds aforementioned that target VEGFR1, VEGFR2 and VEGFR3, MAZ51 primarily targeted VEGFR3 in this study. It remains to be determined if VEGFR3 inhibition in the presence of VEGFR1/2 inhibition will display similar activity. It also remains to be determined if it would be more efficient to control the differentiation and functions of tumor-associated macrophages (TAMs) in order to improve chemosensitivity in lung adenocarcinoma. In addition, our study was limited to lung adenocarcinoma. Further research is warranted to determine if the expression of p53 and PTEN are also regulated by VEGFR3 in other solid tumors.

Our research will continue in the future. We hypothesize that since VEGFR3 inhibition can enhance the chemosensitivity of lung adenocarcinoma cells from the tumor itself, then possibly VEGFR3 inhibition can control the differentiation and functions of TAMs. If possible, VEGFR3 inhibition will have a dual role, it will affect the tumor itself to enhance 
the sensitivity of chemotherapy, in addition to altering the microenvironment (from M2 to M1) in order to enhance the sensitivity of chemotherapy. If the experiment can be ascertained, then VEGFR3 has a great clinical value.

In conclusion, we found that TAMs induced the expression of VEGF-C and its receptor VEGFR3 in cancer cells. VEGFR3 blockade resulted in the upregulation of proteins p53 and PTEN, the induction of cell cycle arrest, and chemosensitization. Given the observation that the overexpression of proteins p53 and PTEN in lung adenocarcinoma cells display a much better prognosis than p53- and PTEN-deficient tumors, our results imply that VEGFR3 inhibition, through upregulation of p53 and PTEN, is a critical clinical target for lung adenocarcinoma. VEGFR3 inhibition would allow p53- and PTEN-deficient patients to benefit through improved clinical outcomes. In addition, VEGFR3 inhibition would allow chemosensitization for p53- and PTEN-deficient tumors.

\section{Acknowledgements}

The study was supported by the National Natural Science Foundation of China (NSFC 81672103 and NSFC 31200971), the National Ministry of Education Foundation of China, (20115503110009) and by the Program of the Ministry of Science and Technology of Yu-Zhong District, CQ (20130136).

\section{References}

1. Siddiqui S, Ali MU, Ali MA, Shah N and Nasreen S: Lung carcinoma: Its profile and changing trends. J Ayub Med Coll Abbottabad 22: 116-119, 2010.

2. Suzuki H, Takahashi T, Kuroishi T, Suyama M, Ariyoshi Y, Takahashi T and Ueda R: p53 mutations in non-small cell lung cancer in Japan: Association between mutations and smoking. Cancer Res 52: 734-736, 1992.

3. Tsao MS, Aviel-Ronen S, Ding K, Lau D, Liu N, Sakurada A, Whitehead M, Zhu CQ, Livingston R, Johnson DH, et al: Prognostic and predictive importance of p53 and RAS for adjuvant chemotherapy in non small-cell lung cancer. J Clin Oncol 25: 5240-5247, 2007.

4. Ferlay J, Shin HR, Bray F, Forman D, Mathers C and Parkin DM: Estimates of worldwide burden of cancer in 2008: GLOBOCAN 2008. Int J Cancer 127: 2893-2917, 2010.

5. Mayo LD, Dixon JE, Durden DL, Tonks NK and Donner DB: PTEN protects p53 from Mdm2 and sensitizes cancer cells to chemotherapy. J Biol Chem 277: 5484-5489, 2002.

6. Agarwal ML, Taylor WR, Chernov MV, Chernova OB and Stark GR: The p53 network. J Biol Chem 273: 1-4, 1998.

7. Müller I, Niethammer D and Bruchelt G: Anthracycline-derived chemotherapeutics in apoptosis and free radical cytotoxicity (Review). Int J Mol Med 1: 491-494, 1998.

8. Zhu T, Li LL, Xiao GF, Luo QZ, Liu QZ, Yao KT and Xiao GH: Berberine increases doxorubicin sensitivity by suppressing STAT3 in lung cancer. Am J Chin Med 43: 1487-1502, 2015.

9. Li ZL, Chen C, Yang Y, Wang C, Yang T, Yang X and Liu SC: Gamma secretase inhibitor enhances sensitivity to doxorubicin in MDA-MB-231 cells. Int J Clin Exp Pathol 8: 4378-4387, 2015.

10. Schreiber RD, Old LJ and Smyth MJ: Cancer immunoediting: Integrating immunity's roles in cancer suppression and promotion. Science 331: 1565-1570, 2011.

11. Watkins SK, Egilmez NK, Suttles J and Stout RD: IL-12 rapidly alters the functional profile of tumor-associated and tumor-infiltrating macrophages in vitro and in vivo. J Immunol 178 $1357-1362,2007$

12. Martinez FO, Gordon S, Locati M and Mantovani A: Transcriptional profiling of the human monocyte-to-macrophage differentiation and polarization: New molecules and patterns of gene expression. J Immunol 177: 7303-7311, 2006.

13. Mills CD: M1 and M2 macrophages: Oracles of health and disease. Crit Rev Immunol 32: 463-488, 2012.
14. Martinez FO and Gordon S: The M1 and M2 paradigm of macrophage activation: Time for reassessment. F1000Prime Rep 6: 13, 2014.

15. Mantovani A, Sozzani S, Locati M, Allavena P and Sica A: Macrophage polarization: Tumor-associated macrophages as a paradigm for polarized M2 mononuclear phagocytes. Trends Immunol 23: 549-555, 2002.

16. Mitchem JB, Brennan DJ, Knolhoff BL, Belt BA, Zhu Y, Sanford DE, Belaygorod L, Carpenter D, Collins L, Piwnica-Worms D, et al: Targeting tumor-infiltrating macrophages decreases tumor-initiating cells, relieves immunosuppression, and improves chemotherapeutic responses. Cancer Res 73: 1128-1141, 2013.

17. Gonzalez FJ, Vicioso L, Alvarez M, Sevilla I, Marques E, Gallego E, Alonso L, Matilla A and Alba E: Association between VEGF expression in tumour-associated macrophages and elevated serum VEGF levels in primary colorectal cancer patients. Cancer Biomark 3: 325-333, 2007.

18. Schoppmann SF, Fenzl A, Nagy K, Unger S, Bayer G, Geleff S, Gnant M, Horvat R, Jakesz R and Birner P: VEGF-C expressing tumor-associated macrophages in lymph node positive breast cancer: Impact on lymphangiogenesis and survival. Surgery 139: 839-846, 2006.

19. Schoppmann SF, Birner P, Stöckl J, Kalt R, Ullrich R, Caucig C, Kriehuber E, Nagy K, Alitalo K and Kerjaschki D: Tumor-associated macrophages express lymphatic endothelial growth factors and are related to peritumoral lymphangiogenesis. Am J Pathol 161: 947-956, 2002.

20. Yao X, Ping Y, Liu Y, Chen K, Yoshimura T, Liu M, Gong W, Chen C, Niu Q, Guo D, et al: Vascular endothelial growth factor receptor 2 (VEGFR-2) plays a key role in vasculogenic mimicry formation, neovascularization and tumor initiation by glioma stem-like cells. PLoS One 8: e57188, 2013.

21. Hamerlik P, Lathia JD, Rasmussen R, Wu Q, Bartkova J, Lee M, Moudry P, Bartek J Jr, Fischer W, Lukas J, et al: Autocrine VEGF-VEGFR2-neuropilin-1 signaling promotes glioma stem-like cell viability and tumor growth. J Exp Med 209: 507-520, 2012.

22. Arinaga M, Noguchi T, Takeno S, Chujo M, Miura T and Uchida Y: Clinical significance of vascular endothelial growth factor $\mathrm{C}$ and vascular endothelial growth factor receptor 3 in patients with nonsmall cell lung carcinoma. Cancer 97: 457-464, 2003.

23. Niki T, Iba S, Tokunou M, Yamada T, Matsuno Y and Hirohashi S: Expression of vascular endothelial growth factors A, B, C, and D and their relationships to lymph node status in lung adenocarcinoma. Clin Cancer Res 6: 2431-2439, 2000.

24. Timoshenko AV, Rastogi S and Lala PK: Migration-promoting role of VEGF-C and VEGF-C binding receptors in human breast cancer cells. Br J Cancer 97: 1090-1098, 2007.

25. Lee E, Koskimaki JE, Pandey NB and Popel AS: Inhibition of lymphangiogenesis and angiogenesis in breast tumor xenografts and lymph nodes by a peptide derived from transmembrane protein 45A. Neoplasia 15: 112-124, 2013.

26. Roberts N, Kloos B, Cassella M, Podgrabinska S, Persaud K, Wu Y, Pytowski B and Skobe M: Inhibition of VEGFR-3 activation with the antagonistic antibody more potently suppresses lymph node and distant metastases than inactivation of VEGFR-2. Cancer Res 66: 2650-2657, 2006.

27. Alam A, Blanc I, Gueguen-Dorbes G, Duclos O, Bonnin J, Barron P, Laplace M-C, Morin G, Gaujarengues F, Dol F, et al: SAR131675, a potent and selective VEGFR-3-TK inhibitor with antilymphangiogenic, antitumoral, and antimetastatic activities. Mol Cancer Ther 11: 1637-1649, 2012.

28. Alitalo AK, Proulx ST, Karaman S, Aebischer D, Martino S, Jost M, Schneider N, Bry M and Detmar M: VEGF-C and VEGF-D blockade inhibits inflammatory skin carcinogenesis. Cancer Res 73: 4212-4221, 2013.

29. Ostrand-Rosenberg S: Immune surveillance: A balance between protumor and antitumor immunity. Curr Opin Genet Dev 18: 11-18, 2008.

30. Biswas SK, Allavena P and Mantovani A: Tumor-associated macrophages: functional diversity, clinical significance, and open questions. Semin Immunopathol 35: 585-600, 2013.

31. Qian BZ and Pollard JW: Macrophage diversity enhances tumor progression and metastasis. Cell 141: 39-51, 2010.

32. Kerjaschki D: The crucial role of macrophages in lymphangiogenesis. J Clin Invest 115: 2316-2319, 2005. 
33. Chung ES, Chauhan SK, Jin Y, Nakao S, Hafezi-Moghadam A, van Rooijen N, Zhang Q, Chen L and Dana R: Contribution of macrophages to angiogenesis induced by vascular endothelial growth factor receptor-3-specific ligands. Am J Pathol 175: 1984-1992, 2009.

34. Mitsudomi T, Oyama T, Kusano T, Osaki T, Nakanishi R and Shirakusa T: Mutations of the p53 gene as a predictor of poor prognosis in patients with non-small-cell lung cancer. J Natl Cancer Inst 85: 2018-2023, 1993.

35. Beer DG, Kardia SL, Huang CC, Giordano TJ, Levin AM, Misek DE, Lin L, Chen G, Gharib TG, Thomas DG, et al: Gene-expression profiles predict survival of patients with lung adenocarcinoma. Nat Med 8: 816-824, 2002.

36. Gibbons DL, Byers LA and Kurie JM: Smoking, p53 mutation, and lung cancer. Mol Cancer Res 12: 3-13, 2014.

37. Chen Z, Fillmore CM, Hammerman PS, Kim CF and Wong KK: Non-small-cell lung cancers: A heterogeneous set of diseases. Nat Rev Cancer 14: 535-546, 2014

38. Tang JM, He QY, Guo RX and Chang XJ: Phosphorylated Akt overexpression and loss of PTEN expression in non-small cell lung cancer confers poor prognosis. Lung Cancer 51: 181-191, 2006

39. Inoue A, Narumi K, Matsubara N, Sugawara S, Saijo Y, Satoh K and Nukiwa T: Administration of wild-type p53 adenoviral vector synergistically enhances the cytotoxicity of anti-cancer drugs in human lung cancer cells irrespective of the status of p53 gene. Cancer Lett 157: 105-112, 2000.

40. Dunkern TR, Wedemeyer I, Baumgärtner M, Fritz G and Kaina B: Resistance of p53 knockout cells to doxorubicin is related to reduced formation of DNA strand breaks rather than impaired apoptotic signaling. DNA Repair (Amst) 2: 49-60, 2003.

41. Meng RD, Phillips P and El-Deiry WS: p53-independent increase in E2F-1 expression enhances the cytotoxic effects of etoposide and of adriamycin. Int J Oncol 14: 5-14, 1999.
42. Liu ZL, Wang H, Liu J and Wang ZX: MicroRNA-21 (miR-21) expression promotes growth, metastasis, and chemo- or radioresistance in non-small cell lung cancer cells by targeting PTEN. Mol Cell Biochem 372: 35-45, 2013.

43. Pan L, Lu J, Wang X, Han L, Zhang Y, Han S and Huang B: Histone deacetylase inhibitor trichostatin a potentiates doxorubicin-induced apoptosis by up-regulating PTEN expression. Cancer 109: 1676-1688, 2007.

44. Khromova N, Kopnin P, Rybko V and Kopnin BP: Downregulation of VEGF-C expression in lung and colon cancer cells decelerates tumor growth and inhibits metastasis via multiple mechanisms. Oncogene 31: 1389-1397, 2012.

45. Chen H, Ding X, Gao Y, Jiang X, Liu X, Chen Y, Gao J, Zhou X, Cai Z and Sun Q: Inhibition of angiogenesis by a novel neutralizing antibody targeting human VEGFR-3. Mabs 5: 956-961, 2013.

46. Albuquerque RJ: The newest member of the VEGF family. Blood 121: 4015-4016, 2013.

47. Sallinen H, Anttila M, Narvainen J, Koponen J, Hamalainen K, Kholova I, Heikura T, Toivanen P, Kosma V-M, Heinonen S, et al: Antiangiogenic gene therapy with soluble VEGFR-1, -2, and -3 reduces the growth of solid human ovarian carcinoma in mice. Mol Ther 17: 278-284, 2009.

48. Yang H, Kim C, Kim MJ, Schwendener RA, Alitalo K, Heston W, Kim I, Kim WJ and Koh GY: Soluble vascular endothelial growth factor receptor-3 suppresses lymphangiogenesis and lymphatic metastasis in bladder cancer. Mol Cancer 10: 36, 2011.

49. Mir O, Brodowicz T, Italiano A, Wallet J, Blay J-Y, Bertucci F, Chevreau C, Piperno-Neumann S, Bompas E, Salas S, et al: Safety and efficacy of regorafenib in patients with advanced soft tissue sarcoma (REGOSARC): A randomised, double-blind, placebo-controlled, phase 2 trial. Lancet Oncol 17: 1732-1742, 2016. 